\title{
The Delegates
}

\section{BY STATE, FROM NORTH TO SOUTH, WITH THE QUORUM EACH STATE REQUIRED}

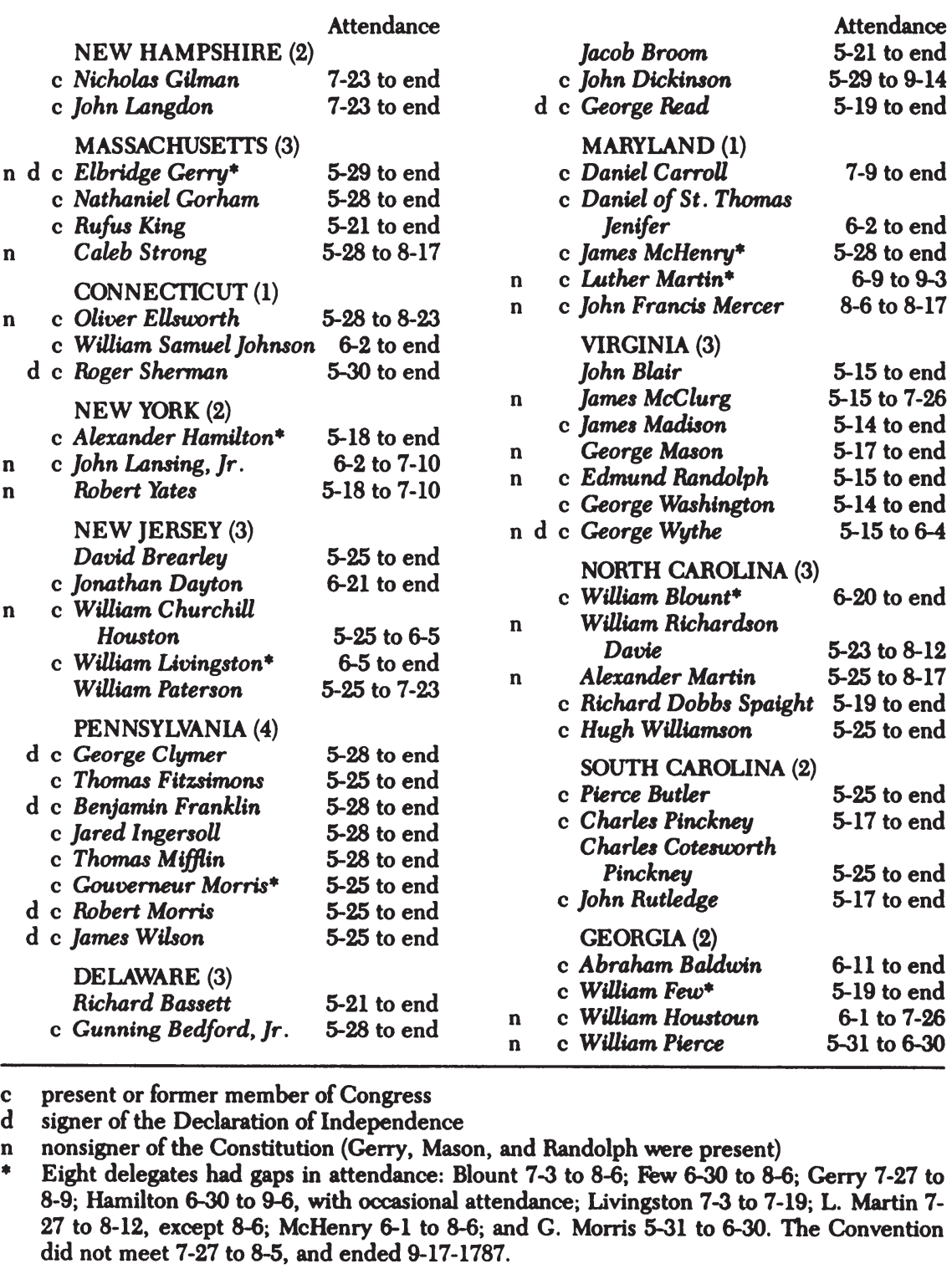

Attendance

$7-23$ to end

$7-23$ to end

c John Dickinson

Ceorge Read

MARYLAND (1)

c Daniel Carroll

Daniel of St. Thomas Jenifer

c James McHenry*

n c Luther Martin*

VIRGINIA (3)

John Blair

James McClurg

James Madison

c Edmund Randolph

c George Washington

5-25 to end

$5-25$ to $6-5$

6-5 to end

William Livingston*

William Paterson

5-28 to end

5-25 to end

5-28 to end

$5-28$ to end

5-25 to end

5-25 to end

5-25 to end

GEORGLA (2)

c Abraham Baldwin

c William Few*

5-19 to end

6-1 to 7-26

n William Houstoun

n William Pierce

Attendance

5-29 to $9-14$

5-19 to end

-28 to end

6-9 to $9-3$

5-15 to end

5-14 to end

$5-17$ to end

5-15 to end

$5-14$ to end

6-20 to end

5-23 to $8-12$

5-19 to end

5-25 to end

5-25 to end

5-25 to end

5-17 to end

(n) 
This page intentionally left blank. 